\title{
Influência das Instituições no Desempenho Econômico Industrial Latino-americano: Um Estudo Quantitativo com Dados em Painel
}

\author{
Influence of Institutions on Economic Performance \\ of Latin American Industrial Sector: A Quantitative \\ Study with Panel Data
}

\author{
Paulo Eduardo Moledo Palombo(i) \\ Antonio Carlos Aidar Sauaia $a^{(*)}$
}

\begin{abstract}
Resumo: A análise das influências institucionais sobre a conduta empresarial tem, segundo Eggertsson (1990) e Black (2000), espaço para o uso de novos ferramentais quantitativos. Com a econometria de dados em painel examinaram-se 24 países da América Latina em 17 anos de observação. Das quinze variáveis estudadas, sete explicaram o desempenho do PIB industrial: efetividade da ação governamental (+), qualidade regulatória dos três poderes (-), proporção do crédito disponível no mercado em relação ao PIB (+), liberdade para comercializar com o exterior $(+)$, despesas e gastos governamentais em proporção do PIB (-), índice de percepção de corrupção $(-)$ e população $(+)$ como variável de controle. Tais resultados destacam a importância das instituições no desempenho do setor industrial latino-americano, no período estudado.
\end{abstract}

Palavras-chave: Instituições; Desempenho Econômico Industrial; Dados em Painel

\begin{abstract}
According to Eggertsson (1990) and Black (2000) new quantitative tools should be used for the analysis of institutional influences on corporate behavior. In this quantitative study we adopted the econometrics of panel data, and examined 17 years of observations of 24 countries in Latin America. Seven out of fifteen variables explained the performance of the industrial GDP: the effectiveness of government action (+), the regulatory quality of the three powers $(-)$, the proportion of available credit in the market relative to GDP (+), freedom to trade with the outside world $(+)$, government spending as a proportion of GDP $(-)$, corruption perception index $(-)$ and the population $(+)$ as a control variable. The results reinforce the importance of institutions on the performance of Latin American industrial sector during the study period.
\end{abstract}

Keywords: Institutions, Economic Performance Industrial, Panel Data

(*) Professor Doutor da Universidade Presbiteriana Mackenzie. E-mail:<palombo@mackenzie.com.br>.

(**) Professor Associado-FEA/USP e Coordenador do Grupo dePesquisas SIMULAB. E-mail:<asauaia@usp.br>. Recebido em 7.6.2011 e aceito em 3.10.2011. 


\section{INTRODUÇÃO}

A análise das influências institucionais sobre a conduta empresarial tem, segundo Eggertsson (1990) e Black (2000), espaço para o uso de novos ferramentais quantitativos. Os autores apontam deficiências a serem sanadas: a incipiente coleta de dados institucionais, principalmente nos países em desenvolvimento e a complexidade de uma análise institucional comparada. O objetivo neste estudo é buscar indícios na literatura e evidências nas análises quantitativas de que regras institucionais influenciaram a estrutura do setor industrial, a conduta dos agentes e o desempenho econômico industrial dos países latino-americanos.

Os estudos da influência das instituições sobre o desempenho industrial ganharam relevância à medida que a economia brasileira se abriu para o comércio internacional após os anos 90, evidenciando a importância de se entender também os ambientes institucionais dos outros países parceiros. Adicionalmente, a recente crise financeira do subprime em 2008, ocorrida nos EUA e cujos efeitos são sentidos presentemente, reabriu a discussão sobre a urgência de maior regulação do mercado por parte dos governos e sobre o fortalecimento das instituições para a redução dos efeitos das incertezas e das especulações decorrentes.

Diversas pesquisas têm estudado aspectos relacionados com a estrutura tributária brasileira, seus incentivos e desincentivos ao processo produtivo privado, os mecanismos de financiamento público e oneração do setor privado, as restrições orçamentárias públicas e o processo de desenho e ordenamento institucional.

Diferentemente dos demais estudos, o objetivo desta pesquisa foi desenvolver um questionamento e estudar as influências das instituições e suas regras na estrutura setorial, na conduta dos agentes e no desempenho das empresas do setor industrial. Na comparação de diferentes ambientes institucionais latino-americanos, buscaram-se neste estudo elementos que pudessem indicar se instituições ou regras institucionais são de fato relevantes para influenciar o desempenho setorial, identificando-se quais variáveis são mais influentes e qual é o sinal dessa influência, se positivo ou negativo.

A metodologia da pesquisa baseou-se no uso de dados macroeconômicos e setoriais da indústria brasileira e de outros 23 países latino-americanos estudados, usando-se observações de um período de 17 anos. Por meio da análise econométrica de variáveis institucionais, com o uso de dados em painel, avaliaram-se neste estudo as ações do ator Governo no sentido de propiciar oportunidades ou ameaças ao setor industrial e seus agentes.

Por meio dessa base, estudou-se a influência de mudanças institucionais tais como: alterações na qualidade regulatória do governo, de percepção de corrupção, de efetividade governamental na implantação de políticas públicas e na liberdade do país para o comércio internacional, além do índice Doing Business do Banco Mundial, que ranqueia o país quanto ao ambiente para fazer negócios. Na pesquisa, utilizaram-se dados econômicos, políticos e institucionais analisados por meio do software STATA, para distinguir as variáveis com significância estatística, capazes de explicar o desempenho econômico setorial da indústria.

As variáveis com maior significância indicadas pelo modelo econométrico foram: a importância da efetividade da ação governamental $(+)$, a qualidade regulatória dos três 
poderes (-), a proporção do crédito em relação ao PIB dada ao mercado $(+)$, a liberdade para comercializar com o exterior $(-)$, despesas e gastos governamentais em proporção do $\operatorname{PIB}(-)$, o índice de percepção de corrupção $(-)$ e a população $(+)$ como variável de controle.

Os resultados desta pesquisa sinalizam oportunidades aos gestores de instituições públicas e privadas para reavaliarem a importância que têm dado às variáveis políticas, institucionais e econômicas. Servem também aos formuladores de políticas públicas para que estejam atentos aos efeitos das instituições e suas regras sobre a estrutura dos setores industriais, a conduta e o desempenho dos agentes econômicos e, finalmente, paras as instituições de ensino reaproximarem tópicos teóricos e ferramentas práticas das literaturas gerencial e econômica, das Ciências Sociais Aplicadas.

\section{Instituições - TeOrias e Definições}

O desenho das instituições constitui um dos aspectos mais importantes para o desenvolvimento e o crescimento econômico de um país (WILLIAMSON, 1985), pois elas podem influenciar a estrutura setorial e a conduta dos agentes econômicos. Por conseguinte, qualquer mudança ou alteração nessas instituições serão também relevantes e devem ser analisadas. Trata-se aqui de uma revisão quanto às mudanças institucionais e suas definições presentes na literatura (EGGERTSSON, 1990).

Abordagens teóricas de mudança institucional nas economias em transição e em desenvolvimento já são bastante diversificadas, pois vão desde as teorias gerais do processo de reforma como um todo, por meio de modelos muito específicos, até as teorias da reforma institucional com aspectos particulares. A abordagem mais geral é a de Roland (2000), cujos modelos foram muito bem estabelecidos em inúmeros artigos.

Roland (2000, p. 87) considerou graduais as abordagens chamadas Big Bang para a reforma institucional de uma economia de mercado e investigou a formação de vários tipos de coligação, em favor ou contra, nas diferentes etapas da reforma. Embora sem focalizar diretamente as questões institucionais centrais desse trabalho, Stiglitz (1996, p. 102) chamou a atenção para as deficiências do modelo neoclássico, um padrão da economia de mercado, como base para um aconselhamento aos governos de países em transição e em desenvolvimento sobre as estratégias adequadas de reforma institucional.

Stiglitz (1996, p. 82) alertou sobre numerosas questões informativas e de incentivo que surgem em muitos mercados, como a resolução teórica que implica várias formas de intervenção e regulação pelo Estado. Este autor deu contribuição relevante ao fornecer uma base conceitual para viabilizar reformas institucionais, essenciais aos Estados em que se pretende atingir o estágio de desenvolvimento de uma economia de mercado.

O resultado dessa análise pode gerar um desenho utilizando-se da economia da informação, que pode levar a notáveis conclusões, como por exemplo, na análise dos mercados de crédito e bancos, no papel da concorrência na privatização e nos direitos de propriedade (MOOSA, 2002, p. 56). 
Ao contrário da definição de instituições acima referida, várias economias em transição e em desenvolvimento criaram práticas que comprometem gerando um conflito com as características desejáveis aqui listadas. Em particular, a propriedade do anonimato é frequentemente violada mediante formas de captura do Estado por grandes empresas e outros grupos de interesse econômico, nas quais esses agentes são capazes de influenciar a política estatal em seu favor e, consequentemente, prejudicar o bom funcionamento das instituições econômicas e políticas (STIGLITZ, 1996, p. 92).

O desenho institucional influencia o desenho do Estado, podendo até sobrepor-se a ele; portanto, a primeira consequência direta da formulação das instituições é a formação das relações entre Estado e Sociedade, ou Estado e setores econômicos privados (CHIAROMONTE; DOSI, 1991). De modo objetivo, são trazidas definições de distintos desenhos de Estado, que possuem por sua vez tipos díspares de relação com os setores produtivos privados.

\section{Governo como Agente Incentivador do Crescimento Econômico Setorial}

O redesenho do Estado para facilitar e promover o desenvolvimento econômico passa pela mudança direta e profunda de suas estruturas organizacionais, tornando eficiente sua gestão e incorporando técnicas modernizantes (KLIKSBERG, 1994, p. 38). Estudam-se com frequência crescente maneiras de tornar o governo um importante e eficiente incentivador do crescimento econômico setorial. Para isso, é preciso discutir, qual a função que se deseja para o Estado nos países em desenvolvimento e, no caso específico deste estudo, no Brasil deste início de século. As mudanças e modernizações técnicas, absolutamente necessárias, não podem ser escolhidas de forma abstrata ou a partir da oferta de tecnologias do mercado (COWLING, 1999, p. 72).

Devem existir critérios de escolha guiados pela ideia central de que, dada uma função ou serviço a ser oferecido pelo Estado, indaga-se qual seria o tipo de tecnologia mais apropriada para possibilitar que ele cumpra, com a maior eficiência possível, essa função (KLIKSBERG, 1994, p. 42; MOOSA, 2002, p. 71).

A discussão tecnocrática pura simples sobre a reforma do Estado para o desenvolvimento econômico setorial deveria ser superada por um debate mais amplo que, partindo dos novos posicionamentos com respeito aos modelos de desenvolvimento, extraia conclusões sobre quais seriam os papéis do Estado eficiente e, a partir daí, procurar elaborar critérios técnicos para dotá-lo das capacidades com que consiga concluí-los (CROZIER, 1996, p. 63).

O questionamento sobre a função do Estado nas questões econômicas faz parte de uma polêmica mais ampla sobre a função geral do Estado e sua relação com a sociedade que o desenhou. Esteve situado, por algumas décadas, na ideia de que era possível pensar-se num Estado que planificasse integralmente o desenvolvimento em todos seus aspectos. Os exemplos típicos da Alemanha Oriental e da ex-União Soviética mostraram existir desincentivos e problemas econômicos graves. Provocam-se ineficiências por meio das limitações de informações e controle de sua máquina, ao planejar e trabalhar centralizadamente para levar a cabo esta operação que assumisse todo tipo de funções executivas, o que seria impensável 
em virtude da complexidade dos atuais sistemas econômicos (KLIKSBERG, 1994, p. 43; COWLING, 1999, p. 78).

Na prática, esta teoria mostrou graves dificuldades em sua própria criação, subestimando ou marginalizando a sociedade civil em suas múltiplas expressões, sem permitir sua participação, assim como evidenciaram-se as dificuldades na implantação efetiva de políticas públicas. Revelaram-se sérias ineficiências, além do caráter centralizado da gestão que se mostrou rígida e muito distante das exigências da realidade, que se altera com uma rapidez cada vez maior e requer Estados que evoluam com velocidade. O pêndulo girou para a direção em que se postulava a necessidade de um Estado mínimo (KLIKSBERG, 1994, p. 43; GONÇALVES, 2003, p. 53).

No caso do Estado centralizador, pode-se ainda citar o problema dos custos de transação, pois ao se tentar planificar a economia como um todo, gerenciar tal quantidade de informações necessárias para a tomada de decisão, tornava o processo muito caro, ineficiente e quase impossível de operar (DOSI; EGIDI, 1991, p. 17).

No caso do Estado mínimo, experiências como a crise de 1929 e a Grande Depressão mostraram que o modo de produção capitalista também apresenta suas falhas e que o mercado em determinadas condições não consegue alocar os recursos de maneira eficiente. Com a finalidade de se atingir um equilíbrio, tornou necessária e imprescindível a intervenção estatal no sentido de alterar as características da estrutura do mercado em questão, em particular no exemplo dos mercados acionário e imobiliário (ERICSON, 2000, p. 69).

A regulação surge como uma necessidade de garantia da eficiência econômica e uma percebida aspiração e vontade da sociedade, perante os custos enormes que a sociedade toda poderá pagar, caso sejam entregues a certa mão invisível alguns de seus aspectos críticos ou estratégicos, com o perigo da formação de cartéis, ou até mesmo monopólios. Crozier (1996, p. 64) adverte com respeito a isso: "Com muita frequência, a mão invisível de Adam Smith se transforma na mão de um punguista. Os mercados livres e sem amarras têm o costume de descobrir atividades muito rentáveis, mas improdutivas."

Um Estado concentrado em funções estratégicas para a sociedade, com um desenho institucional e um desenvolvimento de capacidades gerenciais que lhe permitam concretizá-las com alta eficiência, é o que se espera de um Estado misto, incentivador do crescimento econômico setorial. Nestes esquemas, identifica-se que, entre Estado e mercado, existe um amplo conjunto de organizações, que inclui, entre outras, os espaços de interesse público. Organizações sem fins lucrativos, nem totalmente públicas, nem privadas cujo fim é a maximização da utilidade coletiva. Como exemplos: a nova geração de cooperativas empresariais com extensa difusão em numerosos países desenvolvidos e em desenvolvimento, as organizações não governamentais, as organizações sociais voluntárias de base religiosa, as organizações de bairros, os grupos ecologistas, o voluntariado e outras formas de agrupamento de esforços da sociedade civil de múltiplas características (MINTZBERG, 1996a, p. 22).

Trata-se, na nova concepção, de se adicionar às funções-chave do Estado para a sociedade essas funções vinculadas com demandas como as que foram antes expostas e outras que o Estado pode desempenhar, juntamente com as potencialidades do mercado e as múltiplas contribuições que podem emanar da sociedade civil. Parte daí a obrigação de se 
repensar o Estado, tendo como objetivo plausível a conformação do que se poderia chamar um Estado eficiente economicamente e politicamente. É imprescindível continuar o esforço de reconstruir um Estado que venha a cumprir e dar conta das novas demandas que se apresentam e possa se aliar, contribuir e conseguir harmoniosamente junto às forças produtivas privadas a obtenção do melhor resultado para os setores econômicos, sociedade, consumidores, investidores e outros stakeholders e sendo um fator incentivador e facilitador do desenvolvimento de uma sociedade civil cada vez mais articulada, forte e pró-ativa, constituindo-se portanto, um Estado misto incentivador do mercado e dos agentes (SCHERER, 1970, p. 59; PHARR, 1979, p. 39; KLIKSBERG, 1994, p. 43; RAPACZYNSKI, 1996, p. 99).

\section{Metodologia de Pesquisa}

Este estudo inspirou-se em Eggertsson (1990), North (1991, 1994), Havrylyshyn e Rooden (2000), Braga (2002) e Kon (2006) pois, segundo eles, a análise da influência das instituições sobre a economia e o desempenho setorial têm muito a evoluir com o uso mais amplo e constante de métodos quantitativos e evidências empíricas e a introdução de novos ferramentais teórico-analíticos. Segundo esses autores, há uma limitação na coleta de dados políticos e institucionais, principalmente em países em desenvolvimento e uma embrionária construção de base de dados. Há ainda a dificuldade de se compararem diferentes instituições em distintos países, em razão das particularidades sociais e culturais delas. Scherer (1970) usou um método teórico de comparação, com uma abordagem quantitativa a partir de tabelas, estudando a Europa Ocidental e os EUA.

Neste estudo, realizou-se uma revisão da literatura que abrangeu os temas: instituições; sua importância para o ambiente econômico; governo como agente do crescimento econômico setorial; falhas institucionais; e o desenho institucional para reduzir as incertezas econômicas colaborando para o desempenho econômico.

Utilizou-se da análise de dados por meio de uma regressão feita pela econometria de painel, a ser descrita na próxima seção. Com uma ampla amostra de 24 países da América Latina coletada de um período de 17 anos de observação e de dados secundários, buscou-se trazer para o estudo uma robustez maior em sua estrutura analítica, sua metodologia, seus resultados e conclusões.

Utilizaram-se algumas variáveis de controle: população e inflação, variáveis macroeconômicas, tais como a proporção do crédito em relação ao PIB, alíquota efetiva do Imposto de Renda do capital estrangeiro, para analisar seus efeitos sobre o desempenho no PIB setorial das indústrias. Além disso, o aspecto político também foi considerado, ao se estudar se ele pode efetivamente alterar o desempenho econômico setorial da indústria a partir da maior ou menor liberdade política civil.

\section{Método Econométrico - Modelos de Efeitos Fixos}

Ao se adotar aqui modelos de efeitos fixos, depara-se com modelos cujos coeficientes podem variar de indivíduo para indivíduo, ou ainda na mesma unidade de observação, com 
o passar do tempo, ainda que permaneçam como constantes fixas, não aleatórias (GREENE, 2008, p. 81). Estabeleceu-se a equação econométrica simples (1):

$$
Y_{i, t}=\alpha_{i}+\beta_{1} X_{i, t i, t}+\varepsilon_{i, t}
$$

Em (1) $\Upsilon$ é a variável dependente, $\alpha$ é ocoeficiente angular da equação, $\beta$ é o vetor de coeficientes associados às variáveis explicativas independentes, $X$ são os valores assumidos pelas variáveis explicativas, para toda e qualquer unidade de observação, $\varepsilon$ é o termo de perturbação genérico, ou o erro não explicado pelo vetor das variáveis explicativas, $i$ é o conjunto de unidades de observação e té o período de observações coletado (GREENE, 2008).

Para testar se as mudanças institucionais realmente causaram algum impacto, realizam-se estimativas utilizando Least Squares Dummy Variable Model — LSDV. A amostra de 24 países latino-americanos situou-se entre os anos de 1992 e 2009. Em face da disponibilidade de dados para este estudo econométrico, foram analisados: Antígua e Barbado, Argentina, Bahamas, Bolívia, Brasil, Chile, Colômbia, Costa Rica, República Dominicana, Equador, El Salvador, Guiana, Haiti, Honduras, Jamaica, México, Nicarágua, Panamá, Paraguai, Peru, Suriname, Trinidad e Tobago, Uruguai e Venezuela.

Dentre esses países, alguns cenários estudados evoluíram para a estabilidade, enquanto outros seguiram no caminho oposto. Destaque-se a existência de variáveis semelhantes colhidas por institutos multilaterais e apartidários o que permitiu uma comparação econométrica interessante entre os países para o período de 1992 a 2009.

A influência temporal sobre as variáveis e os resultados econométricos foi testada e não se apresentou com significância estatística elevada. Portanto, não se observou uma tendência temporal de crescimento econômico setorial da indústria por si só, de modo isolado, em decorrência das variáveis políticas, institucionais e de controle.

No Quadro 1, sintetizaram-se as variáveis e fontes de dados utilizadas para a realização da econometria com dados em painel, trazendo também uma descrição sucinta para facilitar o entendimento dos modelos aqui formulados.

Foram utilizados todos os anos disponíveis de observações de 1992 a 2009, com a totalidade de dados das bases apresentadas no Quadro 1 (WORLD BANK; FRASER INSTITUTE; TRANSPARENCY INTERNATIONAL; FREEDOM HOUSE). Para processar as regressões no software STATA, foram numeradas as unidades de observação, os 24 países latino-americanos. Foram usados os códigos oficiais do Banco Mundial para cada país. A variável dependente analisada de cada país foi o PIB industrial deflacionado para isolar-se o efeito da inflação nas variáveis explicativas.

A variável explicativa 2-capital_cont, ou controle de capitais, segundo Della Porta (2000) e Braga (2002) deveria apresentar um coeficiente positivo (+), indicando influência positiva sobre o PIB industrial. Quanto maior o controle de capitais, maior a possibilidade de o país permitir somente a entrada de Investimentos Estrangeiros Direto, com baixa presença de investimento especulativo para beneficiar o setor industrial. 


\section{Quadro 1 - Descrição e fontes das variáveis dos modelos de regressão}

\begin{tabular}{clll}
\hline & Variáveis & Descrição Sucinta & $\begin{array}{l}\text { Fonte/ } \\
\text { Instituição }\end{array}$ \\
\hline 1 & anos & Número de anos apresentados nas bases internacionais (1992-2009). & World Bank \\
\hline 2 & capital_cont & Controle de capitais estrangeiros. & Fraser Institute \\
\hline 3 & cod_pais & $\begin{array}{l}\text { Código do Banco Mundial que identifica o país em diferentes bases } \\
\text { de dados internacionais. }\end{array}$ & World Bank \\
\hline 4 & corruption & Índice de percepção de corrupção, de o a 10; quanto maior, melhor, & Transparency \\
& & sendo menor é a percepção de corrupção no país. & International \\
\hline 5 & desp_gov & Gastos com despesa do governo geral como proporção do PIB. & Fraser Institute \\
\hline 6 & efet_gov & Efetividade da ação governamental. & Fraser Institute \\
\hline 7 & free_house & Classificação quanto à liberdade política. Dummy: 1 se livre; o se & Freedom House \\
\hline 8 & gdp_deflator & PIB industrial deflacionado para se isolar o efeito inflacionário. & World Bank \\
\hline 9 & income_tax & A maior alíquota do imposto de renda praticada. & Fraser Institute \\
\hline 10 & infla & Taxa de inflação corrente anualizada. & World Bank \\
\hline 11 & legal_struct & Classificação quanto à eficiência da estrutura legal e segurança dos & Fraser Institute \\
\hline 12 & mkt_cred & Crédito em proporção do PIB. & Fraser Institute \\
\hline 13 & pop & Número de habitantes do país. & World Bank \\
\hline 14 & reg_qualy & Qualidade dos marcos regulatório. & Fraser Institute \\
\hline 15 & trade_free & Liberdade para o comércio internacional. & Fraser Institute \\
\hline
\end{tabular}

Fonte: Elaborado pelos autores a partir das fontes citadas.

A variável 4-corruption, ou corrupção, segundo Della Porta (2000) apareceria com um coeficiente negativo (-), pois quanto maior a percepção da população e dos empresários maior deveria ser o custo para investimentos e operações das empresas do setor industrial e, portanto, menores seriam os investimentos e menor o PIB industrial. Para a variável 5-desp_gov, ou proporção da despesa pública em relação ao PIB, esperar-se-ia um coeficiente negativo (-) de acordo com Elsner e Groenewegwn (2000), pois quanto maiores fossem as despesas públicas em relação ao PIB, maior seria o consumo público e maior a concorrência com as empresas por bens, serviços e fatores de produção, o que elevaria o custo e reduziria o PIB industrial.

Para a variável 6-efet_gov, ou efetividade da ação governamental, o coeficiente esperado seria positivo $(+)$, pois quanto maior a efetividade pública na aplicação de leis aprovadas e esperadas pela sociedade, maior a confiança e estabilidade político-institucional e seu efeito seria positivo para o resultado do PIB industrial, segundo Grigorian e Martinez (2001).

O coeficiente da variável 7-free_house, que mede quão livre é a sociedade para manifestar vontades políticas (livre, parcialmente livre ou não livre), apareceria com sinal positivo (+), pois de acordo com Black (2000) quanto maior a liberdade política de uma sociedade maior é a proximidade do desenho das políticas públicas com as aspirações da sociedade e maior seria a eficiência e eficácia dessas políticas o que beneficiaria o setor industrial que também poderia expor suas dificuldades e interesses para os formuladores das políticas públicas e econômicas. 
Quanto à variável 9-income_tax, ou a maior alíquota do imposto de renda vigente no país, seu coeficiente de acordo com os estudos de Cowling (1999) e Braga (2002) seria negativo (-), pois quanto maior a tributação sobre os lucros ou receitas das empresas, maiores seriam os custos e menor seria a capacidade de novos investimentos, inibindo o crescimento econômico industrial.

A variável 10-infla, correspondente à taxa de inflação oficial divulgada pelos governos, é uma variável de controle utilizada em estudos como os de Lagos (2001 e 2003) e Hellman et al. (2010) para estudar o efeito inflacionário sobre o processo de planejamento e decisões de investimentos. Quanto maior a inflação, maior a dificuldade para realizar planejamentos de longo prazo, por causa das variações nos custos de produção.

O coeficiente da variável 11-legal_struct, ou eficiência da estrutura legal do país seria positivo (+) segundo Rapaczynski (1996) e Black (2000), pois quanto maior a eficiência do marco regulatório legal dos países, maior seria a estabilidade institucional, a transparência no funcionamento dos mecanismos legais e mais rápidas seriam as decisões judiciais, o que beneficiaria o setor industrial.

A variável 12-mkt_cred, ou proporção de crédito em relação ao PIB, é uma variável de controle que deve ser observada segundo Roland (2000) e Kon (2006), pois é uma das condicionantes econômicas mais relevantes para o sucesso do setor produtivo privado de um país, principalmente o industrial, sendo fundamental para a capacidade de investimentos em produtividade e competitividade e, por conseguinte, na geração de crescimento econômico. A variável 13-pop, ou população, foi outra variável adotada como controle. Tem uma relação positiva $(+)$ com o desempenho econômico industrial, pois quanto maior a população, maior a oferta de mão de obra e maior o mercado consumidor potencial (TEECE et al., 1977).

Para a variável 14-reg_qualy, ou qualidade dos marcos regulatórios, seria esperado um coeficiente positivo (+), pois de acordo com Teece et al. (1997) e Kon (2006), quanto maiores a qualidade, estabilidade e transparência dos marcos regulatórios, maior seria a estabilidade institucional do ambiente no qual o setor industrial atua, beneficiando assim um maior crescimento econômico. A variável 15-trade_free, ou liberdade para o comércio internacional, teria uma relação positiva $(+)$ com o PIB industrial no caso de economias avançadas e negativa no caso de economias em desenvolvimento, pois de acordo com Stiglitz (1996), Roland (2000), Braga (2002) e Kon (2006), para o segundo grupo, o comércio internacional seria menos vantajoso pelas vantagens comparativas e barreiras comerciais, causando prejuízos ao setor industrial.

\section{Resultado da Regressão do Modelo Geral}

O aplicativo STATA em sua versão 10.0 foi o software utilizado para realizar os testes econométricos. Foi adotada como variável dependente o Produto Interno Bruto Industrial deflacionado (gdp_deflator). Apresentam-se nesta seção os resultados principais das regressões com o valor do coeficiente (Coef.), sendo que este valor não indica uma relação numérica proporcional entre ele e sua influência na explicação da variável dependente. O sinal do coeficiente indica se essa relação de influência entre a variável independente e a 
dependente é positiva ou negativa. Para auxiliar na explicação da variável dependente e seu valor nas tabelas de probabilidade, foi calculado o t-student $(\mathrm{P}>\mathrm{t})$, indicando quando a variável mostrou-se estatisticamente significante. As colunas da Tabela 1 são referentes aos resultados das regressões e correspondem às saídas principais da análise de um estudo econométrico (GREENE, 2008).

De acordo com a Tabela 1, foram sete as variáveis significantes no modelo para explicar a conduta do PIB industrial deflacionado: a efetividade da ação governamental, com um coeficiente positivo e significante, indicando que quanto maior a efetividade na aplicação das leis, maior a estabilidade institucional e maior o PIB industrial; a qualidade da regulação do país com um coeficiente negativo, o que demonstra que quanto mais burocrático é o país, pior é o resultado do PIB industrial isso a um nível de significância de 1\%. Foram utilizadas 139 observações nesta estimação econométrica.

Com relação à "proporção de crédito dada ao mercado", encontrou-se um coeficiente positivo e significante ao nível de $5 \%$, o que indica que quanto maior o volume do crédito, maior será o crescimento do PIB, com um R2 ajustado de 0,72 (valor que varia de 0 a 1 ). Este resultado, segundo Greene (2008), é um excelente valor para indicar o poder explicativo do modelo sobre a variável dependente.

Tabela 1 - Resultados econométricos para o modelo geral

\begin{tabular}{cccc}
\hline Variáveis & gdp_deflator & Coef. & t \\
\hline $\mathbf{1}$ & efet_gov*** & $\mathbf{1 6 5 7 . 5 8}$ & $\mathbf{0 . 0 0 8}$ \\
\hline $\mathbf{2}$ & reg_qualy*** & $\mathbf{- 2 . 4 8 2 . 7 8 5}$ & $\mathbf{0 . 0 0 3}$ \\
\hline $\mathbf{3}$ & mkt_cred** & $\mathbf{1 8 6 4 6 . 1 9}$ & $\mathbf{0 . 0 1 3}$ \\
\hline $\mathbf{4}$ & trade_free* & $\mathbf{- 2 5 9 0 6 . 5 8}$ & $\mathbf{0 . 0 8 6}$ \\
\hline 5 & capital_cont & 7.153 .277 & 0.119 \\
\hline 6 & legal_struct & 2.593 .714 & 0.778 \\
\hline 7 & income_tax & $\mathbf{1 . 7 4 6 . 9 8 4}$ & 0.293 \\
\hline $\mathbf{8}$ & desp_gov*** & $\mathbf{- 1 . 9 2 4 . 0 6 5}$ & $\mathbf{0 . 0 0 0}$ \\
\hline 9 & free_house & $\mathbf{- 2 9 6 1 9 . 1 9}$ & 0.186 \\
\hline $\mathbf{1 0}$ & corruption $* *$ & $\mathbf{- 4 1 2 6 7 . 2 2}$ & $\mathbf{0 . 0 1 5}$ \\
\hline $\mathbf{1 1}$ & pop*** & $\mathbf{3 . 0 2 9 . 8 3 7}$ & $\mathbf{0 . 0 0 0}$ \\
\hline 12 & infla_ & $\mathbf{1 . 2 6 6 . 6 7 7}$ & 0.803 \\
\hline & constante & $\mathbf{- 7 3 1 8 4 . 1 5}$ & 0.019 \\
\hline
\end{tabular}

Legenda: *** grau de significância de $1 \%$; ** grau de significância de 5\%; *grau de significância de $10 \%$. Fonte: Elaborada pelos autores a partir dos resultados da regressão no STATA 10.0.

O coeficiente da variável "liberdade do comércio" indicou uma influência negativa ao nível de $10 \%$ de significância, que pode ser explicada por fatores de competitividade, dado que quanto maior é a abertura maior a possibilidade de entrada de produtos externos. $\mathrm{Na}$ variável "gastos públicos do governo", obteve-se o resultado esperado com sinal negativo e significante ao nível de 1\%. Quanto maior o consumo do governo, maior sua concorrência com o setor privado por fatores de produção e por bens e serviços privados.

Para as duas últimas variáveis significantes do modelo, encontraram-se os sinais esperados: negativo para a variável "corrupção", com nível de significância de 5\%, indicando que quanto 
maior é o índice de percepção de corrupção do país, pior é o desempenho do PIB industrial. Para a variável "população" obteve-se um coeficiente significante ao nível de $1 \%$ e positivo, indicando que quanto maior a população maior o mercado consumidor interno, maior a abundância do fator trabalho e melhor é o desempenho do PIB industrial.

As demais variáveis não foram significantes: capital_cont, ou controle de capitais; legal_struct, ou eficiência da estrutura legal; income_tax, ou a maior alíquota do imposto de renda; free_house, ou liberdade política civil; e infla, ou inflação. Quanto à variável capital_cont, uma das razões possíveis para a sua não significância ao analisar a base de dados poderia ser a inexistência do controle sobre o capital estrangeiro nos países da América Latina, o que de acordo com Hetherington (2004) ocorre em face da necessidade da entrada de investimentos estrangeiros, mesmo especulativos. Para a variável legal_struct, assim como para a free_house, havia poucos anos de observação, o que pode ser uma razão para a não significância estatística na explicação da variável dependente. Quanto às variáveis income_tax e infla, existe uma variabilidade muito grande entre elas de país para país. Alguns países na América Latina como Venezuela têm altas alíquotas máximas de imposto de renda e elevadas taxas de inflação, enquanto países como o Chile têm alíquotas máximas pequenas e também baixas taxas de inflação. Segundo Greene (2008), estes podem ser indícios de explicações para as não significâncias estatísticas dessas variáveis independentes.

\section{Teste de Robustez do Modelo Geral e Discussão dos Resultados Econométricos}

Foram realizados testes de robustez para os resultados encontrados no modelo geral. No primeiro tipo de teste baseado em Greene (2008), foram retiradas todas as variáveis explicativas e de controle e, a seguir, incluídas progressivamente uma a uma para testar se alguma delas ampliava ou reduzia o poder de explicação, ou a significância de outra. $\mathrm{O}$ segundo teste consistiu na retirada de todas as unidades observacionais da amostra e inclusão progressiva uma a uma, o que permitiu uma análise de influência entre os entes observados, teste esse denominado Chow Preditive ou Falha Preditiva (GREENE, 2008). Seu resultado não indicou sobreposição de explicação das unidades da amostra.

Por meio desses testes, percebeu-se que cinco variáveis significativas mantiveram-se significantes durante os testes de retirada e inclusão progressiva de variáveis, apontando a importância desses indicadores institucionais para o desempenho setorial da indústria, a saber: efetividade governamental, liberdade para o comércio internacional, percepção de corrupção, crédito ao mercado e regulação do governo.

Quanto ao teste de retirada e inclusão progressiva dos países latino-americanos da amostra, também se observou que nenhum deles apresentou sua estatística p-valor significante, ao nível de $1 \%, 5 \%$ ou $10 \%$. Assim, nenhum deles trouxe viés para qualquer uma das variáveis observadas, nem sobre a amostra, de modo a alterar ou influenciar significativamente os resultados do modelo econométrico. Portanto, segundo Greene (2008), o modelo aqui descrito e seus resultados não possuem vieses de amostra quanto às unidades observacionais escolhidas, ou às variáveis inseridas no modelo, o que permite que se ampliem as conclusões advindas delas para casos mais gerais. 
Tais inclusões trouxeram evidências positivas para validade do modelo, assim como para sua robustez, pois na maior parte absoluta as variáveis que se mantiveram significantes, assim como seus sinais em relação à variável dependente. Foram utilizadas 169 observações nesta estimação econométrica.

Tabela 2 - Resultados econométricos para o modelo simplificado

\begin{tabular}{cccc}
\hline & gdp_deflator & Coef. & T \\
\hline $\mathbf{1}$ & efet_gov* & $\mathbf{3 2 . 6 4 6 8 7}$ & $\mathbf{0 . 0 9 8}$ \\
\hline $\mathbf{2}$ & reg_qualy*** & $\mathbf{- 3 0 6 8 . 8 1}$ & $\mathbf{0}$ \\
\hline $\mathbf{3}$ & mkt_cred*** & $\mathbf{2 4 2 3 8 . 4 4}$ & $\mathbf{0 . 0 0 1}$ \\
\hline $\mathbf{4}$ & trade_free*** $^{*}$ & $\mathbf{- 3 0 4 5 2 . 8}$ & $\mathbf{0 . 0 4 7}$ \\
\hline $\mathbf{5}$ & capital_cont* $^{*}$ & $\mathbf{7 7 4 4 . 7 4 9}$ & $\mathbf{0 . 0 5 4}$ \\
\hline $\mathbf{6}$ & desp_gov*** & $\mathbf{- 2 5 5 5 . 4 9}$ & $\mathbf{0}$ \\
\hline 7 & free_house & $\mathbf{- 4 0 8 5 . 0 7}$ & 0.856 \\
\hline $\mathbf{8}$ & corruption $* *$ & $\mathbf{- 3 6 6 4 6 . 7}$ & $\mathbf{0 . 0 2 6}$ \\
\hline & Constante & 506326.2 & 0 \\
\hline
\end{tabular}

Legenda: *** grau de significância de $1 \%$; ** grau de significância de $5 \%$; *grau de significância de $10 \%$. Fonte: Elaborada pelos autores a partir dos resultados da regressão no STATA 10.0.

Por fim, o modelo simplificado da Tabela 2 reúne somente as variáveis significantes dos modelos anteriores para, assim, verificar se uma delas tiraria a significância ou poder de explicação da outra, indicando, por exemplo, a existência de alguma multicolineariedade. Observou-se não haver indícios de multicolineariedade, já que as variáveis se mantiveram significantes a níveis muito próximos aos que anteriormente encontrados e com os sinais de seus coeficientes inalterados. Houve apenas uma exceção, a da variável free_house que já havia demonstrado ser uma variável pouco explicativa e pouco agregadora no poder explicativo do modelo (R2 ajustado de 0,72). Foram utilizadas 159 observações nesta estimação econométrica.

Quadro 2-Resumo dos resultados encontrados no modelo geral e no simplificado

\begin{tabular}{|c|c|c|c|c|c|c|c|c|c|c|c|c|c|c|}
\hline & Variáveis & MG & $\begin{array}{c}\mathrm{M} \\
\mathrm{S} \\
\mathbf{1}\end{array}$ & $\begin{array}{c}\mathrm{M} \\
\mathrm{S} \\
\mathbf{2}\end{array}$ & $\begin{array}{c}\mathrm{M} \\
\mathrm{S} \\
3\end{array}$ & $\begin{array}{c}\mathrm{M} \\
\mathrm{S} \\
\mathbf{4}\end{array}$ & $\begin{array}{c}\mathrm{M} \\
\mathrm{S} \\
\mathbf{5}\end{array}$ & $\begin{array}{c}M \\
S \\
6\end{array}$ & $\begin{array}{c}\text { M } \\
\text { S } \\
7\end{array}$ & $\begin{array}{l}\text { M } \\
\mathrm{S} \\
8\end{array}$ & $\begin{array}{c}\text { M } \\
\text { S } \\
9\end{array}$ & $\begin{array}{c}\mathrm{M} \\
\mathrm{S} \\
10\end{array}$ & $\begin{array}{c}\text { M } \\
\text { S } \\
11\end{array}$ & $\begin{array}{c}\mathrm{M} \\
\mathrm{S} \\
12\end{array}$ \\
\hline 1 & Efet_gov & + *⿻丷木米 & + ***** & + *米米 & 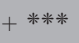 & + 米米米 & 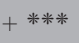 & + 米米米 & 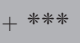 & 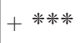 & + * **** & + * *米米 & + * $* * *$ & 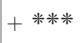 \\
\hline 2 & Reg_qualy & - 米米米 & & - *⿻丷木 $^{*}$ & 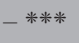 & 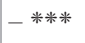 & - 米米米 & - 米米米 & — & - 米米米 & - * **** & 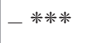 & - ***** & - 米米米 \\
\hline 3 & Mkt_cred & + **⿻丷木 & & & $+* *$ & $+{ }^{*} * *$ & + *** & + 米米 & $+* *$ & + 米米 & + *** & + 米* & + 米米 & + **⿻丷木 \\
\hline 4 & trade_free & $-*$ & & & & - & $-*$ & $-*$ & $-*$ & $-*$ & $-*$ & $-{ }^{*}$ & $-*$ & $-{ }^{*}$ \\
\hline 5 & capital_cont & + & & & & & $+*$ & $+*$ & + & + & + & $+*$ & + & $+*$ \\
\hline 6 & legal_struct & + & & & & & & + & + & + & + & + & + & \\
\hline 7 & income_tax & + & & & & & & & + & - & - & + & + & \\
\hline 8 & Desp_gov & 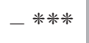 & & & & & & & & - 米米 & - $* * *$ & - 米米米 & 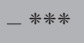 & - 米米米 \\
\hline 9 & Free_house & - & & & & & & & & & + & - & - & - \\
\hline 10 & corruption & - *⿻丷木 $^{\prime}$ & & & & & & & & & & - **⿻丷木 & $-* *$ & - *⿻丷木 $^{2}$ \\
\hline 11 & Pop & + ****** & & & & & & & & & & & + ***** & \\
\hline
\end{tabular}

Legenda: MG - Modelo Geral; MSn - Modelo Simplificado, sendo n 1 a 12; + ou - remete ao sinal encontrado no coeficiente de cada variável em cada modelo rodado; **** grau de significância de 1\%; ***arau de significância de $5 \%$; *grau de significância de $10 \%$.

Fonte: Elaborado pelos autores a partir das análises econométricas 
O Quadro 2 apresenta uma síntese dos resultados obtidos nas regressões rodadas. Foi possível perceber que a variável "efetividade da ação governamental" apareceu com sinal positivo e significante ao nível de pelo menos $10 \%$, indicado pelo asterisco ao lado do sinal positivo, em todas as regressões rodadas. Isto sinaliza um interessante indício para o efeito das intervenções governamentais latino-americanas no desempenho econômico industrial, conforme previram Grigorian e Martinez (2001) ao estudarem outros ambientes econômicos.

As seguintes variáveis apareceram com significância estatística de pelo menos $10 \%$ e com os mesmos sinais, positivos ou negativos, ao longo de todas as regressões, geral ou parciais: qualidade dos marcos regulatórios — reg_qualy, proporção de crédito ao mercado em relação ao PIB - mkt_cred, liberdade para o comércio exterior — trade_free, proporção das despesas públicas com consumo em relação ao PIB - desp_gov, índice de percepção de corrupção e população - corruption e tamanho da população — pop, indicando a robustez do modelo, das variáveis explicativas e das variáveis de controle adotadas.

Quando a variável não apareceu significante nem a 10\%, indicou-se no Quadro 2 apenas o sinal do coeficiente. A não significância estatística ocorreu no caso da variável "qualidade da estrutura legal", da maior alíquota do imposto de renda cobrada - a "income_tax" e da "free_house", que indica quão livre é o país politicamente.

Os resultados obtidos neste estudo corroboram outros encontrados na literatura econômica, segundo Gonçalves (2003) e Moosa (2002) que estudaram o Brasil e os países pertencentes ao G7 - grupo dos sete países mais ricos do mundo: Estados Unidos, Japão, Alemanha, França, Reino Unido, Itália e Canadá. A desaceleração da demanda global já exerceu forte pressão na redução dos preços das commodities pelo mundo. $\mathrm{O}$ caso dos preços do petróleo refletiu-se de forma aguda nas perspectivas de menor crescimento econômico (FMI, 2009). Nos dois estudos, o governo regulou positivamente e atuou diretamente na economia, elevando os resultados na maioria dos setores.

Gonçalves (2003) e Moosa (2002) destacaram os resultados econômicos mais favoráveis após as intervenções e ações governamentais: as elevadas taxas de crescimento do PIB brasileiro que durante o milagre econômico foi, em média, de $8 \%$; as taxas de desemprego nos níveis históricos mais baixos dos países europeus com média de 3\%. Além desses resultados econômicos, os governos propiciaram um ambiente político e institucional mais estável, em economias já desenvolvidas e em desenvolvimento, o que reforça a importância de se estudar tais intervenções e sua percepção pelos gestores das empresas.

Segundo Brennan e Buchanan (1985), o Estado Leviatã busca maximizar seu tamanho a partir da criação e coleta de impostos. Porém, para isso persistir no longo prazo, é necessário o convencimento da sociedade de que há benefícios gerados por parte do governo e que estes são maiores que os custos associados.

Disto advém, segundo Brennan e Buchanan (1985) e Lora e Cárdenas (2006), o fato de a participação na economia dos estados latino-americanos ser maior, quando comparada à dos países da OCDE. Disto subentende-se uma maior efetividade da ação governamental e melhor qualidade na regulamentação pública, que legitimem a alta carga tributária imposta. 
Stein (1999) indica, em sua mais ampla obra, que uma maior percepção de corrupção em países com alta participação estatal na economia pode ser percebida pela proximidade dos agentes públicos e privados. Não necessariamente haveria mais corrupção, mas ela seria mais perceptível do que em países desenvolvidos e com menor participação estatal.

Segundo os dados do Fraser Institute (2010) baseados em relatórios do Fundo Monetário Internacional, os países latino-americanos, apresentam desde 1990 uma constante abertura comercial. No caso brasileiro, este fato levou ao aumento da competitividade industrial com a necessidade de uma ampliação do acesso ao crédito, incentivado como uma política pública institucionalizada. Após anos de economia fechada e sem a capacidade de importação de tecnologia e bens de capital, o aumento de produtividade veio por meio das importações (KON, 2006).

Os elementos teóricos descritos podem embasar os resultados econométricos, ao indicarem a maior necessidade de regulação e efetividade da ação governamental dos países latino-americanos como justificativa das altas cargas tributárias cobradas. Ao mesmo tempo a liberdade para o comércio surgiu como um competidor para a indústria nacional, por depender da importação de tecnologia e bens de capital, em virtude da frágil base de inovação e a baixa especialização massiva da mão de obra. A maior acessibilidade ao crédito pós-estabilização monetária é uma condição necessária, mas não suficiente para a elevação constante da produção e o atendimento da demanda reprimida de bens de consumo industrializados, existente nos países latino-americanos.

Os acontecimentos recentes evidenciaram ainda mais a importância de instituições fortes, ativas e eficientes no socorro aos mercados diante das suas falhas; falhas essas já identificadas em estudos de Microeconomia empírica e em artigos sobre a competitividade e as estruturas de mercado (CHIAROMONTE; DOSI, 1991, p. 79).

Krugman (2008) e Marcovitch (2010) destacaram em suas obras a importância das instituições para assegurarem o funcionamento do mercado dentro de regras estabelecidas, tal que reduzam a assimetria de informação e o risco dos agentes, minimizando a probabilidade de crises se repetirem como a de 2008 , ou fazendo com que um número menor de empresas sofra por não ter acesso igual às informações.

\section{Conclusões e Contribuições}

Algumas deficiências apontadas pelos autores foram superadas neste estudo: a coleta de dados institucionais de 24 países da América Latina por um período de 16 anos constituiu uma ampla base de dados adotada neste estudo, o que permitiu equacionar parte da complexidade de uma análise institucional comparada. Os indícios encontrados na literatura específica constituíram o arcabouço teórico que apoiou o estudo quantitativo e a produção de evidências nas análises econométricas de que algumas regras institucionais influenciaram positiva ou negativamente, de maneira significativa, a estrutura do setor industrial a conduta dos agentes e o desempenho econômico industrial dos países latino-americanos.

Foram replicados para a América Latina alguns resultados de estudos baseados em países da OECD, em particular nas variáveis explicativas que apresentaram elevados níveis 
de significância: efetividade da ação governamental; despesas governamentais; percepção de corrupção; população. Ao contrário, encontraram-se índices com sinais invertidos, também significantes, para as variáveis: qualidade da regulação governamental; liberdade para o comércio.

Ao se discutir a maior regulação do Estado sobre os Mercados, buscou-se complementar ambas as literaturas, a de Economia e a de Gestão, naquilo em cada uma avançou menos, promovendo um diálogo que muitas vezes se mantém adormecido nas Instituições, nas Universidades e nos cursos de graduação, pois se observa que na estrutura curricular básica do curso de Economia há pouco ou quase nada das Ciências Gerenciais, enquanto que no curso de Administração há uma presença relativamente pequena das disciplinas de Economia. Aliando teoria e prática na tentativa de aperfeiçoar a formação dos estudantes de graduação, será possível, também, conduzir relevantes experimentos que serviriam para os próprios educadores melhorarem o foco de suas disciplinas, sua abordagem didática e os testes de avaliação, para que não fiquem reduzidas a avaliações escritas. No caso da econometria em painel, apesar do não controle do experimentador quanto à coleta dos dados e o não conhecimento completo da metodologia de coleta dos mesmos, usaram-se fontes confiáveis e bases de dados secundárias oficiais que muito colaboraram no momento de se desenhar o experimento, e que permitiram interessantes observações acerca das influências de instituições e das políticas governamentais sobre o setor industrial dos diversos países estudados. Tais bases foram levantadas junto a institutos reconhecidos no mercado, parceiros da Universidade de São Paulo e com idoneidade comprovada, como o Fraser Institute do Canadá, uma organização de pesquisa sem fins lucrativos, apoiada pelas universidades HEC Montreal e University of Victoria.

Por sua vez, a distância do experimentador dessa base de dados secundária preveniu algum viés no estudo e garantiu maior validade externa dos resultados econométricos a ser considerada. No modelo econométrico apresentado neste estudo, a primeira variável significante no modelo para explicar o desempenho do PIB industrial deflacionado foi a efetividade da ação governamental, com um coeficiente positivo e significante. Neste sentido, tem-se um indício de que a presença do Estado na economia pode ser benéfica dentro de alguns critérios e condições; com essa variável que mede a totalidade da implantação de políticas públicas após o seu anúncio, indica que o se o governo é eficaz e ativo em sua comunicação e na prática de se fazer políticas, isto reduziria a assimetria de informação por parte do mercado, que se adaptaria com mais facilidade às mudanças praticadas pelas autoridades.

A variável em questão não indicaria a qualidade dessa ação do governo, apenas se ele é ou não efetivo na implantação das políticas anunciadas. Não cabe indicar se esse resultado mostra um ponto positivo ou não na economia desses países, mas deve-se destacar que quanto maior a efetividade na implantação de Políticas Públicas, maior tenderá a ser o desempenho setorial.

Nota-se do ponto de vista do setor industrial a importância de utilizar-se de diferentes ferramentas quantitativas analíticas para examinar um objeto de estudo, não só para obter uma robustez maior em sua análise, mas também para conseguir abarcar um número maior de variáveis observáveis, tanto de dados primários, quanto de secundários. Os gestores da 
indústria poderiam também utilizar-se dessa metodologia para basear parte de seu planejamento e decisões e, pois pelas evidências encontradas neste estudo, as variáveis exógenas, sejam elas institucionais, políticas ou econômicas são influentes no desempenho setorial, ajudando a explicar seu comportamento. Sendo assim, apresentaram-se aqui contribuições do ponto de vista metodológico e empírico para os gestores de instituições e para as organizações industriais e seus setores.

Não se teve a pretensão aqui de encerrar a discussão sobre a importância das instituições ou trazer uma resposta definitiva sobre seu desenho ou influência no desempenho econômico, mas de aproximar a literatura gerencial e a econômica e trazer mais elementos empíricos para essa discussão que, após a crise financeira internacional de 2008, ganhou extrema importância.

\section{Limitações e Proposições Para Novos Estudos}

As limitações presentes neste estudo poderão ser objeto de avanço futuro: ampliar a base de dados dos países utilizada no estudo econométrico usando-se, por exemplo, países da OCDE - Organização para Cooperação do Desenvolvimento Econômico, que agrupa os países mais ricos do mundo, para assim realizar uma análise nova comparada dos resultados entre países latino-americanos e dessa organização.

De posse das variáveis significativas identificadas nesta pesquisa, será possível desenhar experimentos feitos com alunos da graduação em Administração da FEA/USP, em semestres encadeados, de modo a avaliar a influência de diferentes estruturas institucionais no setor, na conduta dos agentes e no desempenho das indústrias.

Há ainda a possibilidade de se usar outras formas de análise metodológica na medida em que a ciência econométrica avançar, adotando-se modelos de regressão mais avançados e eficientes, que possam corrigir eventuais falhas presentes neste estudo. Poderá ser oportuno o uso outros softwares mais completos e com maior possibilidade de corrigir e controlar eventuais problemas e limitações das amostras.

Outro tema passível de estudo seria analisar se a importância de intervenções econômicas por parte do governo tem seus efeitos ou resultados diminuídos por conta de haver uma maior interação de atores econômicos, ante um maior número de variáveis exógenas, não passíveis de controle por parte do governo local.

\section{REFERÊNCIAS BIBLIOGRÁfICAS}

BLACK, Bernard. The legal and institutional preconditions for strong securities markets, Olin Program in Law and Economics, Working Paper 179, Stanford Law School (for thcoming in UCLA Law Review), 2000.

BRAGA, Marcio. Integração econômica regional na América Latina: Uma interpretação das contribuições da CEPAL. Cadernos PROLAM, ano 1, volume 1, p. 48-78, São Paulo, 2002. 
BRENNAN, Geofrey; BUCHANAN, James. The Reason of Rules: Constitutional Political Economy. New York: Cambridge University Press, 1985.

CHIAROMONTE, Francesca; DOSI, Giovanni. The Micro Foundations of Competitiveness and their Macroeconomic Implications, in: Foray, D., Freeman, C. (eds.); Technology and the Wealth of Nations: the dynamics of constructed advantages. London: Pinter, 1991.

COWLING, Keith. Industrial policy in Europe: Theoretical perspectives and practical proposals. Washington, DC: The World Bank, mimeo. April, 1999.

CROZIER, Michel. La transición del paradigma burocrático a una cultura de gestión pública. Revista del Clad, Reforma y Democracia. Caracas, jan. 1996.

DELLA PORTA, Donatella. Social capital, beliefs in government, and political corruption. In: PHARR, S.; PUTNAM, R. D. (Eds.). Disaffected democracies: what's troubling the trilateral countries? Princeton: Princeton University Press, 2000.

DOSI, Georg; EGIDI, Michael. Substantive and Procedural Uncertainty: an Exploration of Economic Behaviours in Changing Environments. Journal of Evolutionary Economics, Abril, 1991.

EGGERTSSON, Thráinn. Economic Behavior and Institutions. Cambridge Surveys of Economic Literature, Cambridge: CUP, 1990.

ELSNER, Wolfram; GROENEWEGEN, John. Industrial Policies after 2000. Dordrecht: Kluwer Academic Publishers, 2000.

ERICSON, Richard. The Russian economy: Market in form but "Feudal" in content. Mimeo, 2000.

FRASER, The Institute. Relatório econômico, político e institucional do órgão de pesquisa ligado ao governo do Canadá. Disponível em: <www.fraserinstitute.org> Último acesso em: ago. 2010. GONÇALVES, Reinaldo. A nova economia internacional: uma perspectiva brasileira. Rio de Janeiro: Elsevier, 2003.

GREENE, William. Econometric Analysis. (6 $6^{\text {th }}$ ed.) New Jersey: Pearson Prentice Hall, 2008.

GRIGORIAN, David; MARTINEZ, Albert. Industrial growth and quality of institutions: What do (transition) economies have to gain from the rule of law?. World Bank Working Paper 2475, Washington, DC: The World Bank, 2001.

HAVRYLYSHYN, Oleh; VAN ROODEN, Ron. Institutions matter in transition, but so do policies. IMF Working Paper, WP/OO/70, Washington, DC: International Monetary Fund. 2000.

HELLMAN, Joel; SCHANKERMAN, Mark. Intervention, corruption and capture: The nexus between enterprises and the state. Public Choice Journal, vol.8 (3), p. 545-576, 2010.

HETHERINGTON, Marc. Why trust matters: declining political trust and the demise of American liberalism. Princeton: Princeton University Press, 2004.

KLIKSBERG, Bernardo. Redesigning the State profile for social and economic development and change. International Review of Administrative Sciences, jun. 1994.

KON, Anita. O comércio internacional da indústria de serviços: os impactos no desenvolvimento de países da América Latina. Cadernos PROLAM/USP, ano 5, vol. 2, p. 9-47, 2006.

KRUGMAN, Paul. The return of depression economics and the crisis of 2008. Londres: Penguin. 2008. LAGOS, Marta. Between stability and crisis in Latin America. Revista de Administração Pública, Rio de Janeiro, v. 32, p. 137-45, fev./mar. 2003.

A road with no return? Public Choice Journal, v. 14, n. 2, p. 163-173, 2003. 
LORA, Eduardo; CÁRDENAS, Maurício. La reforma de las institituciones fiscals en América Latina. BID Working Paper Series 559, 2006.

MARCOVITCH, Jacques. A crise mundial e a construção do futuro. Revista USP [on-line], n.85, p. 6-15. ISSN 0103-9989. 2010.

MINTZBERG, Henry. Managing Government. Government Management. Harvard Business Review, maio/jun. 1996.

MOOSA, Imad. Foreign direct investment: theory, evidence, and practice. Houndmills, Basingstoke, Hampshire; New York: Palgravem, 2002.

NORTH, Douglass. Institutions. Journal of Economic Perspectives, v. 5, n. 1, winter, p. 97-112, 1991.

PHARR, Susan. Officials' misconduct and public distrust: Japan and the trilateral democracies. In: Perspective of the World, London: Fontana Press (originalmente publicado em Francês, 1979).

RAPACZYNSKI, Andrzej. The roles of the state and the market in establishing property rights. Journal of Economic Perspectives, vol.10 (2), pp.87-103, 1996.

ROLAND, Gérard. Transition and economics: Politics, markets, and firms. Cambridge, Mass.: MIT Press, 2000.

ROLAND, Gérard; VERDIER, Thierry. Law enforcement and transition. CEPR Discussion Paper 2501, London: CEPR, 2000.

SCHERER, Mark. Industrial Market Structure and Economic Performance. Chicago: Rand McNally, 1970 .

STEIN, Ernesto. Fiscal decentralization and government size in Latin America. Journal of Applied Economics, vol. II n. 2, 357-391, 1999.

STIGLITZ, Joseph. Some lessons from the East Asian Miracle. In: Research observer. The World Bank, ago, 1996.

STREETEN, Paul. Market and States: against minimalism. World Development, v. 21, n. 8, 1993.

TEECE, David; PISANO, Gary; SHUEN, Amy. Dynamic Capabilities and Strategic Management, Strategic Management Journal, 18, for thcoming, 1997.

WILLIAMSON, Oliver. The Economic Institutions of Capitalism. Free Press: New York, 1985. 